Mars demagnetized

Icarus http://dx.doi.org/10.1016/

j.icarus.2011.10.023 (2011)

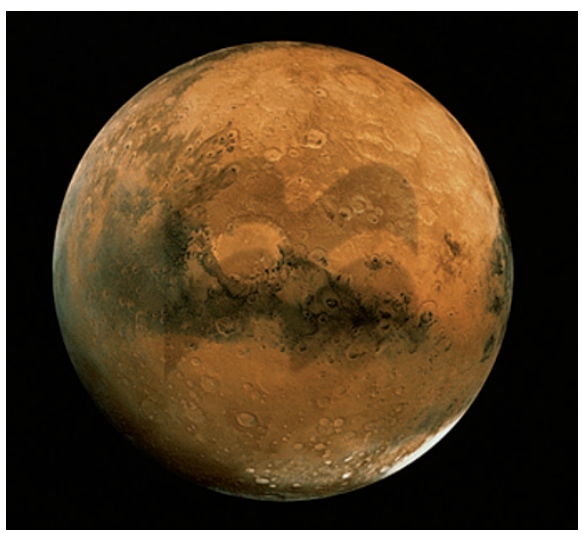

The South Province of Mars is almost devoid of a magnetic signature. Analyses of crustal structure, combined with demagnetization models, suggest that the lack of a magnetic signal here may indicate a weak magnetic field early in Mars's history.

Jafar Arkani-Hamed of the University of Toronto and Daniel Boutin of McGill University, Montreal, tested whether large asteroid impacts on Mars may have re-melted parts of the crust long after the magnetic field had died out, erasing the signature in the South Province. They combined analyses of crustal structure with models of impactinduced demagnetization and found that asteroid impacts in the South Province would have been sufficient to erase any existing magnetic signature around the impact basin. However, they also show that the entire region is devoid of a strong magnetic signal, including areas not affected by impacts.

Rather than undergoing an impactinduced removal of the signature, the entire South Province may have instead formed during a period of weak magnetic field strength on young Mars.

\section{Cretaceous eccentricity}

Paleoceanography http://dx.doi.org/

10.1029/2011PA002163 (in the press)

The middle of the Cretaceous period, beginning about 110 million years ago, was dominated by hot climate conditions. An analysis of carbon in marine rocks reveals that the marine carbon cycle was strongly influenced by changes in the eccentricity of the Earth's orbit during this greenhouse interval.

Martino Giorgioni of ETH Zurich and colleagues measured the carbon isotope composition of carbonates within the midCretaceous marine rocks of the Apennines in Central Italy. They found clear variations on a 400,000-year timescale, in line with long-term variations in the eccentricity of the Earth's orbit. The high eccentricity periods are associated with the deposition of black, organic-rich shales.

The researchers speculate that the longperiod eccentricity cycle induced variations in the geographic distribution and intensity of monsoon systems, as strong monsoons deliver more organic carbon from the continents to the oceans. Orbital forcing could have also affected marine circulation patterns and the storage of carbon in terrestrial wetlands.

\section{Oscillation controls}

Atmos. Chem. Phys. 11, 11679-11687 (2011)

Polar stratospheric temperatures are influenced by solar variability and the quasi-biennial oscillation, which is characterized by regular shifts in the strength and direction of stratospheric winds over the equator. Meteorological data suggest that the combination of these two factors also exerts a significant effect on temperatures throughout large regions of the lower atmosphere.

\title{
Buckled slabs
}

As an oceanic plate descends into the mantle beneath another plate, the subducting slab can bend and buckle. Numerical modelling of subduction shows that buckling in the mantle influences tectonic motions of the plates at the surface.

Changyeol Lee and Scott King of the Virginia Polytechnic Institute and State University simulated slab subduction in two-dimensional numerical experiments. Buckling of the subducted oceanic slab is expressed as the alternating shallowing and steepening of the plate's dip angle as it gradually folds into a concertina in the mantle. The results show that when the plates at the surface converge rapidly the slab subducts at a shallow angle. But when the subducting plate buckles backwards - moving at a steep angle - the rate of convergence between the plates at the surface decreases.

Repeated buckling of subducted slabs over time could explain the different compressional and extensional tectonic features observed at the surface, as well as the varied angles of dip of the slabs observed in subduction zones around the world.

Indrani Roy and Joanna Haigh of Imperial College London assessed the influence of solar variability and the quasi-biennial oscillation on zonal mean temperatures in the troposphere and lower stratosphere across the globe using satellite reanalysis data. They find a significant influence of the combined variables on temperatures in the lower stratosphere. In the troposphere, the influence of the quasi-biennial oscillation is not apparent, but temperatures are affected by solar variability.

The influence of these two variables does, however, appear at the surface, where they modulate sea-level pressure at high latitudes.

\section{Black-carbon burial}

Glob. Biogeochem. Cycles http://dx.doi.org/ $10.1029 / 2010$ GB003956 (in the press)

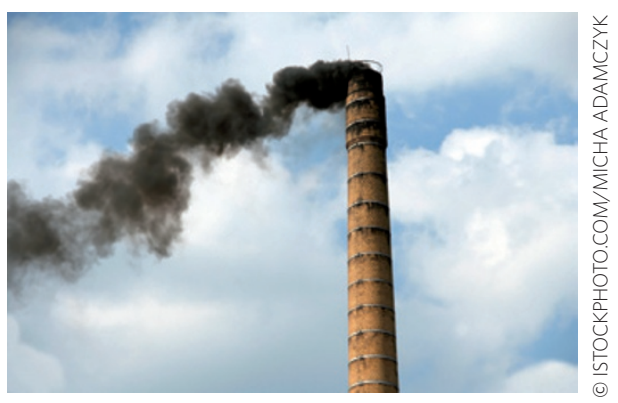

Black-carbon aerosols - derived from the incomplete combustion of fossil fuels and biomass - alter the radiation balance of the planet. An analysis of coastal sediments in Sweden suggests that continental shelf sediments function as a sink for atmospheric black carbon.

Örjan Gustafsson of Stockholm University and colleagues examined the black-carbon content of sediments along a 2,000-km stretch of the Swedish continental shelf. Their analysis focused on the soot form of black carbon, which consists of nanometre- to micrometre-sized particles. Soot black carbon accounts for around 5\% of the organic carbon in the studied sediments. Using previously published sonar data on the extent of sediment accumulation in the region, the researchers estimate that the Swedish continental shelf harbours around $4 \mathrm{Tg}$ of soot black carbon, and sequesters around $300 \mathrm{Gg}$ each year.

Scaling their analysis up, the team estimates that the North European shelf collects 1.1 Tg of soot black carbon from the atmosphere each year - similar in magnitude to European soot black carbon emissions.

Written by Anna Armstrong, Alicia Newton and Amy Whitchurch. 